\title{
ANÁLISE DE ESTRUTURAS E INICIATIVAS DE ESTÍMULO AO EMPREENDEDORISMO NO ENSINO SUPERIOR: UM OLHAR SOB A PERSPECTIVA DISCENTE
}

Paula Karina Salume ${ }^{1}$

Gabriela Figueiredo Dias ${ }^{1}$

Luis Renato Junqueira ${ }^{1}$

${ }^{1}$ Pontifícia Universidade Católica de Minas Gerais - PUC Minas 


\title{
ANÁLISE DE ESTRUTURAS E INICIATIVAS DE ESTÍMULO AO EMPREENDEDORISMO NO ENSINO SUPERIOR: UM OLHAR SOB A PERSPECTIVA DISCENTE
}

\begin{abstract}
RESUMO
As universidades possuem agora a missão de incentivar o empreendedorismo e a inovação, além da promoção do ensino, pesquisa e extensão. Esse estímulo ao empreendedorismo pode ser realizado de diversas formas: disciplinas, eventos, incubadoras, entre outros. O propósito desse estudo é avaliar se universidades e centros universitários de Belo Horizonte, que ofertam cursos de Engenharias e/ou Informática, estimulam o empreendedorismo, levando-se em consideração o ponto de vista discente. Para isso utilizou-se questionários online para compreender a opinião dos alunos acerca do empreendedorismo em sua instituição. Em geral, os estudantes consideram que possuem postura empreendedora e que a metodologia de ensino e a grade curricular contribuem para o desenvolvimento de competências empreendedoras. Por meio de correlações foram analisadas as dimensões do estudo e os resultados apontaram que o apoio dos diretórios estudantis, centros acadêmicos e professores são importantes para o envolvimento dos alunos em iniciativas empreendedoras.
\end{abstract}

Palavras-chave: Educação empreendedora, Empreendedorismo universitário, Universidade empreendedora, Tríplice-hélice.

\section{INTRODUÇÃO}

Diversas transformações ocorreram na sociedade, mudanças especialmente influenciadas pela utilização de novas tecnologias. Nesse contexto, a universidade surge com uma nova missão: além de ser a universidade do ensino, pesquisa e extensão, ela deve contribuir para a criação de novos negócios e ser um berço para a inovação.

Santos (2010) disserta que as instituições de ensino superior possuem como principal função a criação e disseminação do conhecimento e que essas refletem o quadro social de sua época. Como o autor apresenta, a universidade é influenciada pelo momento histórico da sociedade. Em um cenário de mudanças políticas e no mercado de trabalho questiona-se qual a missão das universidades, que sempre tiveram um papel importante (NOVO; MELO, 2003). Casado, Siluk e Zampieri (2012) apresentam que o empreendedorismo, além de outras tendências como a criatividade, aparece como um dos temas característicos do século XXI, período marcado pela informação e conhecimento.

Essa conjuntura requer novas formas de interação da universidade com os outros agentes da sociedade (governo e empresas), além de uma maior interação entre os seus pilares ensino, pesquisa e extensão (AUDY, 2017). No contexto de uma sociedade e um mercado buscando mais conhecimento, também se exige dessa instituição uma maior contribuição para o desenvolvimento, sendo aqui que a Universidade Empreendedora aparece como uma forma de atender a essas demandas (AUDY, 2009).

Em uma pesquisa realizada em 2016 pelo SEBRAE e a Endeavor acerca do tema universidade empreendedora, houve um mapeamento de iniciativas empreendedoras nas universidades brasileiras e do perfil desses universitários. Cerca de 1 em cada 4 alunos possui ou pretende ter um negócio (5,7\% já são empreendedores e $21 \%$ pensam em empreender) e esse 
aluno que já possui um empreendimento está mais inserido no ecossistema empreendedor, ou seja, possui mais experiências ligadas ao empreendedorismo. Ademais, o empreendedor universitário reconhece a importância dos programas da universidade para seu negócio, cerca de $50 \%$ dos alunos que já empreendem ou pretendem empreender acreditam que iniciativas como incubadoras sejam essenciais na preparação para ter um negócio (SEBRAE; ENDEAVOR, 2016).

O presente estudo buscou conhecer e compreender as iniciativas empreendedoras das universidades e centros universitários privados de Belo Horizonte que ofertam cursos de Engenharias e/ou Informática, possibilitando a análise de estruturas e iniciativas de estímulo ao empreendedorismo no ensino superior, sob a perspectiva dos discentes.

Desse modo, procurou-se identificar as iniciativas empreendedoras desenvolvidas nas universidades e centros universitários privados de Belo Horizonte que ofertam cursos de Engenharias e/ou Informática, comparar as atividades empreendedoras desenvolvidas nessas instituições e conhecer a percepção dos discentes acerca dessas iniciativas empreendedoras ofertadas e sua contribuição para a formação do empreendedor.

$\mathrm{O}$ artigo foi estruturado em cinco seções, além dessa introdução. Na segunda seção, nominada "Referencial Teórico", buscou-se discutir, sinteticamente, assuntos relacionados ao empreendedorismo e universidade empreendedora. Outra seção foi oportuna para apresentar os procedimentos metodológicos utilizados na pesquisa. A quarta seção foi criada para expor os resultados da pesquisa e discuti-los. Por fim, na quinta e última seção, as considerações finais do trabalho são apresentadas com foco nas principais conclusões da pesquisa e nos objetivos atingidos, além das limitações do estudo e das sugestões para novos trabalhos.

\section{REFERENCIAL TEÓRICO}

\subsection{Empreendedor}

Ao dissertar acerca do empreendedorismo é de fundamental importância atentar-se para a figura do empreendedor, que é o responsável pelo desenvolvimento do empreendedorismo. A definição de quem é o empreendedor é relevante para entender qual é o seu papel e suas características, entretanto, ao tentar definir o termo percebem-se diferentes interpretações, além de confusões em relação a outros conceitos.

Filion (1999) afirma que ao falar de empreendedorismo deve-se conceituar o termo empreendedor e definir esse termo "é um desafio perpétuo, dada à ampla variedade de pontos de vista usada para estudar o fenômeno". O autor demonstra que na literatura há diferenças na definição devido ao fato de que os teóricos tendem a compreender o empreendedorismo de acordo com a sua área de atuação.

Há certa confusão entre os termos empresário e empreendedor, que em muitos casos são tratados como sinônimos. Os aspectos de inovação e iniciativa são apresentados como características fundamentais do empreendedor, enquanto o empresário possui a função de assegurar a continuidade do empreendimento, e não a de buscar novas oportunidades ou inovar, como o primeiro (MUNIZ, 2008). Filion (1999) também apresenta o contraste entre empreendedor e proprietário-gerente, mostrando que o empreendedorismo não se configura simplesmente do fato de possuir um negócio, pois muitos indivíduos com características empreendedoras não abrem empresas e muitos proprietários que possuem uma empresa, não as criaram, desse modo, não possuem a inovação ou oportunidade que os configurariam como empreendedores. 
O ambiente tem grande influência no surgimento de características empreendedoras, que possibilitam os indivíduos a empreender. Com o estudo acerca do empreendedorismo, percebe-se que o número e atuação de empreendedores em uma dada região está diretamente relacionado com o crescimento dessa, por torná-la um espaço de negócios inovadores e formadora de capital social com elevado nível de conhecimento (TAVARES; MOURA; ALVES, 2013). Consoante com esse pensamento, os autores Martens e Freitas (2006) afirmam que o apoio ao empreendedor por meio de políticas públicas, disponibilidade de recursos e até mesmo o estímulo de uma cultura empreendedora são capazes de desenvolver o empreendedorismo em uma comunidade.

A pesquisa GEM (Global Entrepreneurship Monitor), produzida no Brasil pelo IBQP e o SEBRAE, busca mostrar a situação do empreendedorismo no país, quais são as características dos empreendedores e de seus empreendimentos. No ano de 2017, a taxa total de empreendedorismo foi de 36,40\%, desse total $20,30 \%$ se refere a negócios iniciais. Considerando faixas etárias, percebe-se que a maior parte desses negócios iniciais $(30,50 \%)$ foi criado por jovens na faixa 25 a 34 anos, já os jovens de 18 a 24 anos foram responsáveis pela abertura de 20,3\% desses empreendimentos. Logo, mais de 50\% das empresas em estágio inicial foram criadas por jovens entre 18 a 34 anos, que em números absolutos correspondem a cerca de 5 milhões de brasileiros (SEBRAE; IBQP, 2017).

O empreendedor se configura como o indivíduo que identifica e busca oportunidades, a inovação sendo característica em sua atuação. A atividade empreendedora e o número de indivíduos envolvidos nessa, impulsionam o crescimento econômico de um local. Deve-se recordar que possuir um empreendimento não é fundamental para ser considerado empreendedor.

\subsection{Educação empreendedora}

O empreendedorismo, ligado à inovação e à busca por oportunidades, necessita de um ambiente que apoie os empreendimentos e desenvolva as características empreendedoras nos indivíduos. A Educação Empreendedora se apresenta como um importante elemento para o estímulo dessas características.

No relatório da pesquisa Global Entrepreneurship Monitor (SEBRAE; IBQP, 2017) além dos dados acerca do empreendedorismo, são apresentadas recomendações de especialistas para a melhoria da atividade empreendedora no país. Entre os especialistas, 41,70\% apresentaram sugestões relacionadas à educação e capacitação, e entre essas: aproximar o empreendedorismo da academia, para obter um empreendedorismo mais qualificado e existir uma educação empreendedora desde a educação básica para um futuro com jovens empreendedores.

Ao argumentar sobre a importância da educação na formação dos indivíduos, Santos (2010) disserta que essa tem como finalidade a humanização dos estudantes, que desenvolvem suas capacidades e habilidades a partir do aprendizado. A educação, possuindo importância para o desenvolvimento de capacidades nos indivíduos, pode ser utilizada como ferramenta para o estímulo ao empreendedorismo. Andrade e Torkomian (2001) definem Educação Empreendedora como a promoção de oportunidades pelo indivíduo que pode, a partir dessas, transformar a sua realidade e contribuir para a sociedade que faz parte.

A Educação Empreendedora possibilita ao jovem decidir sobre a sua própria vida, traz um protagonismo para esse, que pode realizar suas próprias escolhas (TAVARES; MOURA; ALVES, 2013). A educação empreendedora foca no aprendizado do aluno, que assume o ponto 
de referência central no processo de aprendizagem, atuando como protagonista e sujeito na buscada autonomia do ser, saber e fazer empreendedor, desse modo, diferenciando de modelos tradicionais de educação (SCHAEFER; MINELLO, 2016). Oliveira, Melo e Muyder (2016) apresentam que as diversas transformações ocorridas demandam novas competências que devem ser desenvolvidas. A educação empreendedora além de se preocupar com a abertura e gestão de negócios deve incentivar empreendimentos que contribuam com a sociedade.

Práticas de Educação Empreendedora têm sido utilizadas em várias instituições de ensino, sobretudo, as de ensino superior. Em todo o mundo, universidades têm desenvolvido programas de Educação Empreendedora, em que o objetivo é não apenas uma formação técnica em seus profissionais, mas uma maior percepção de oportunidades e características importantes para a vida, além de beneficiar o desenvolvimento de empresas. Embora no Brasil já exista algumas iniciativas, deve-se fortalecer a ideia de um programa de Educação Empreendedora, para se desenvolver um Modelo Brasileiro de Programa de Educação Empreendedora adequados ao contexto regional no longo prazo (ANDRADE; TORKOMIAN, 2001). É importante salientar que pela diferença da educação empreendedora e da educação tradicional, devem ser desenvolvidos modelos pedagógicos coerentes com as pretendidas habilidades empreendedoras (SCHAEFER; MINELLO, 2016).

\section{Figura 1 - Características e elementos envolvidos na educação empreendedora CARACTERÍSTICAS DA EDUCAÇÃO EMPREENDEDORA}

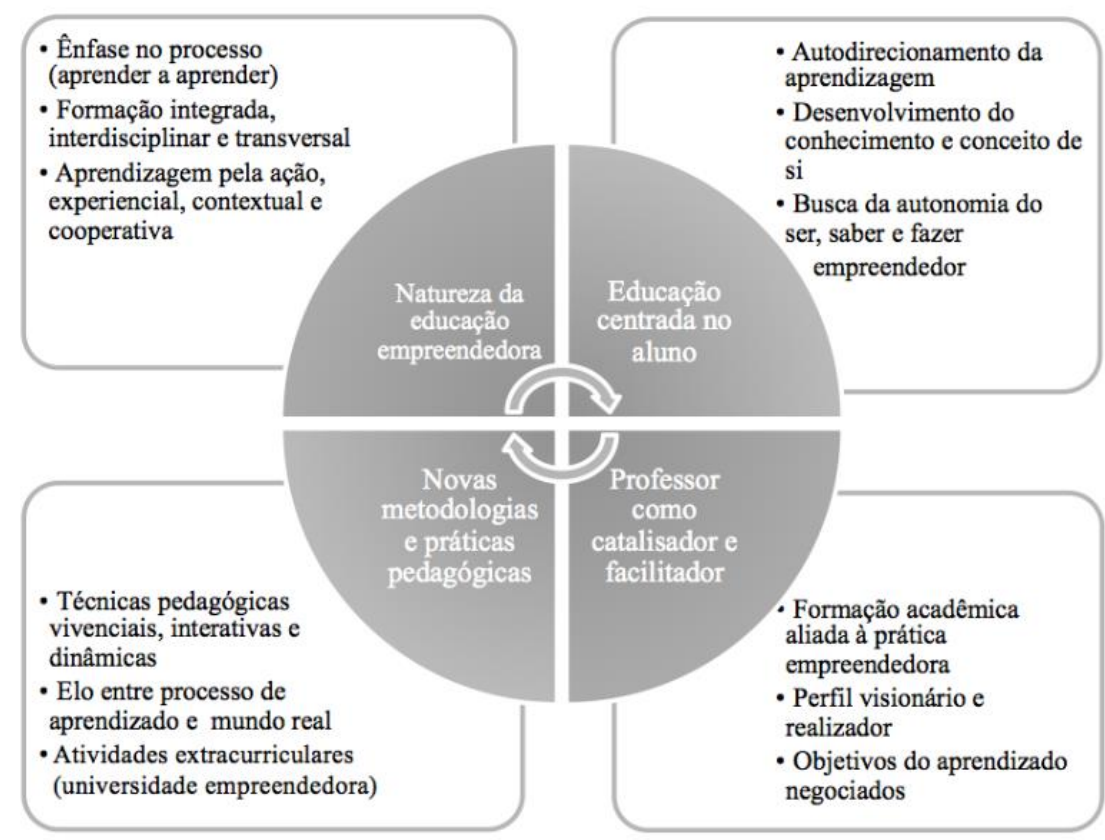

Fonte: Schaefere Minello (2016, p.77)

Diversos estudos indicam que a educação empreendedora no nível superior é fundamental para o desenvolvimento de competências empreendedoras e que o resultado dessa formação é positivo. Por outro lado, há pesquisas que afirmam que a educação no empreendedorismo é contraditória, especialmente por uma possível limitação em seu desenvolvimento. Deve-se levar em conta que, embora se trabalhe aspectos relacionados aos 
conhecimentos do empreendedorismo na educação empreendedora, algumas competências são adquiridas somente na prática ao se encarar sucessos e fracassos (PARREIRA; et al., 2015).

Universidades ao redor do mundo utilizam práticas de Educação Empreendedora, em que a finalidade é desenvolver profissionais que tenham visão de oportunidades. Ademais, com a utilização dessas práticas contribui-se para o aumento do número de empreendimentos, o que, consequentemente, gera desenvolvimento regional em longo prazo.

\subsection{Universidade empreendedora}

A universidade empreendedora surge como uma resposta à exigência por parte da sociedade para que a universidade forme profissionais com características empreendedoras. As instituições, especialmente as de educação superior, possuem diante de um cenário de inovações e tecnologia, a missão de formar profissionais que irão "interagir e produzir nesse ambiente de mudanças e instabilidade" (ANDRADE; TORKOMIAN, 2001, p. 301). A dificuldade que as universidades possuem é a de inserir o ensino do empreendedorismo em todos os seus cursos, de modo a desenvolver a mentalidade empreendedora em seus alunos, independentemente da área de atuação (MARTENS; FREITAS, 2006).

Na pesquisa universidade empreendedora (SEBRAE; ENDEAVOR, 2016) percebeu-se uma relação direta entre cursar uma disciplina de empreendedorismo e o perfil empreendedor do aluno. Dos alunos empreendedores, $46 \%$ já cursaram essas disciplinas, dos potenciais empreendedores, $38,8 \%$, e os que ainda não pensam em ter um negócio, $24 \%$. Um aspecto importante é que são poucos cursos que oferecem essas disciplinas. Dos que ofertam, $50 \%$ são cursos de engenharia e ciências sociais aplicadas (como administração), e em cursos de outras áreas esse índice é de 30\%.

Além de adotar disciplinas de empreendedorismo em seus cursos, uma universidade empreendedora deve possuir em sua filosofia o componente empreendedor, muito mais que apenas adotá-lo em seu currículo de ensino (NOVO; MELO, 2003). Ademais, os autores apresentam que é importante o incentivo às empresas juniores, pré-incubadoras e que as disciplinas estejam presentes em todos os cursos de graduação. Essa não se preocupa somente com a formação de profissionais para o mercado, mas busca contribuir para o desenvolvimento econômico, social e tecnológico, ao possuir estruturas internas e complexas que propiciem a ampliação de empresas de base tecnológica (IPIRANGA; FREITAS; PAIVA, 2010).

A universidade empreendedora é considerada uma instituição que busca a inovação, visando alcançar um novo espaço e uma nova postura no futuro, tomando riscos ao desenvolver práticas de Educação Empreendedora (ALMEIDA; TERRA; ALENCAR, 2016). Para as universidades atuarem como elemento importante no auxílio para o desenvolvimento social e maior inovação, essas devem criar espaços propícios à inovação tal como parques tecnológicos (AUDY, 2009).

Ampliar o ensino do empreendedorismo para todos os cursos da instituição é o desafio da universidade empreendedora, missão que vai além dos pilares ensino, pesquisa e extensão. Para isso, ela deve dispor de vários elementos como empresas juniores, incubadoras, entre outros, para estimular o empreendedorismo nesse contexto.

\subsection{Universidade Tríplice-Hélice}

O conceito de Tríplice-Hélice traz que a universidade, instituição anteriormente responsável pelo ensino, pesquisa e extensão, passa a ter uma responsabilidade tal como o governo e a indústria para a geração de novos negócios (ETZKOWITZ; ZHOU, 2017). 
A universidade necessita que as empresas invistam em tecnologia e em recursos humanos por meio de parcerias, de modo a conseguir responder à demanda das organizações empresariais e de toda a sociedade. E para essa parceria ter melhores resultados se faz necessária a presença e interação com o Estado, agindo como incentivador e financiador desse processo de desenvolvimento (LEITE; DAMA; GRIEBLER, 2013).

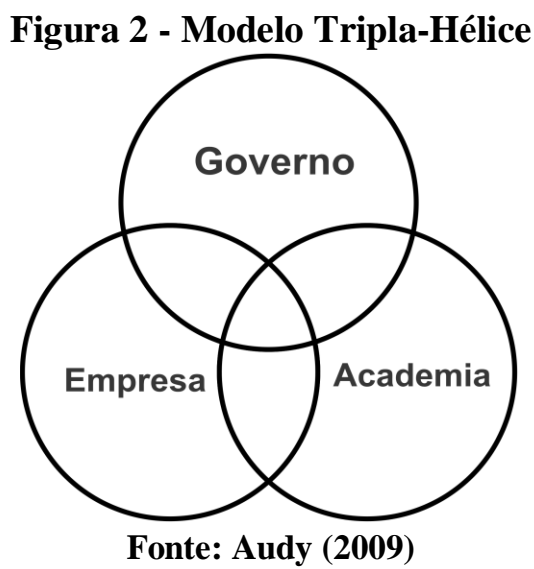

A tripla hélice então se caracteriza como a interação entre os atores empresas, governos e universidade para o desenvolvimento de profissionais capacitados e também a criação de empreendimentos (AUDY, 2017). Há uma articulação entre indústria, governo e universidades.

A universidade tripla-hélice assume uma importância para o desenvolvimento econômico e social tal como o governo e as empresas, e para o sucesso dessa conjuntura faz-se necessária uma cooperação entre esses atores. Em uma nova abordagem, além dos atores indústria, governo e universidade presentes na tríplice se adiciona a sociedade, assim, sendo denominado esse novo contexto de quádrupla hélice.

\section{METODOLOGIA}

Na primeira fase da pesquisa foi realizada uma investigação bibliográfica com a finalidade de aprofundar no tema empreendedorismo no contexto do ensino superior, houve uma investigação acerca da universidade empreendedora e a universidade tripla-hélice. Fonseca (2002) define pesquisa bibliográfica como um estudo que é realizado através do recolhimento de informações já estudadas e definidas por outros pesquisadores. Essa é realizada a partir de material já elaborado, constituído principalmente de livros e artigos científicos (GIL, 2008).

Para a elaboração da fundamentação teórica, utilizaram-se artigos científicos fruto de diferentes fontes como: periódicos científicos, anais de congressos, teses e dissertações, entre outros. Como ferramenta de dados foi utilizado o Google Scholar e entre as expressões utilizadas como descritores: empreendedorismo, educação empreendedora, universidade empreendedora e tripla-hélice.

A fase quantitativa, abordada na segunda fase do projeto, possuiu o objetivo de compreender a cultura empreendedora das instituições pesquisadas, sob a perspectiva dos discentes. A técnica utilizada foi o levantamento ou survey, que se caracteriza por proceder à solicitação de informações a um grupo significativo de pessoas acerca do problema estudado 
para, em seguida e mediante análise qualitativa, obter as conclusões correspondentes dos dados coletados (GIL, 2008).

Figura 3-Elementos Cultura Empreendedora

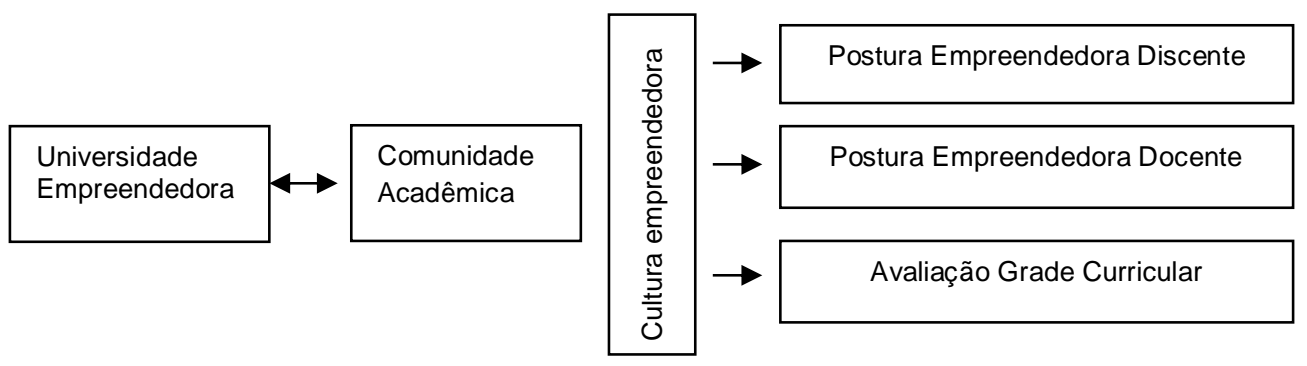

Fonte: Adaptado de Brasil Júnior (2017)

A investigação foi realizada em universidades e centros universitários privados de Belo Horizonte, que oferecem cursos de graduação em Engenharias e/ou Informática: Pontifícia Universidade Católica de Minas Gerais (PUC Minas), Universidade FUMEC (FUMEC), Centro Universitário de Belo Horizonte (UNI-BH), Centro Universitário Newton Paiva (NEWTON PAIVA), Centro Universitário Una (UNA) e Centro Universitário Unihorizontes (UNIHORIZONTES). Para fins de apresentação dos resultados, os nomes foram omitidos.

A amostragem utilizada foi a probabilística, em que todos os alunos dos cursos objetos desta pesquisa das instituições estudadas tiveram a mesma chance de participar do estudo. Em um universo de 31.465 alunos matriculados em cursos presenciais de Engenharia e/ou Informática em centros universitários e universidades localizadas na cidade de Belo Horizonte - Minas Gerais (BRASIL, 2017), aplicou-se a amostragem probabilística, com adoção de intervalo de confiança de $90 \%$ e margem de erro de 5\%, gerando uma amostra de 281 alunos.

Para o cálculo da amostra foi utilizado a seguinte fórmula:

Em que:

$$
n_{0}=\frac{Z(\alpha \mid 2)^{2} \cdot p \cdot q}{e^{2}}
$$

$n_{0}=$ tamanho mínimo da amostra aleatória

$Z(\alpha \mid 2)^{2}=$ estatística $\mathrm{z}$ associada ao intervalo de confiança escolhido

$\mathrm{p}=$ frequência na qual ocorre o evento na população

$\mathrm{q}=$ frequência

$\mathrm{e}=$ margem de erro

Como o número de alunos nos cursos de Engenharia e Informática das universidades e dos centros universitários é finito, as amostras tiveram o seguinte ajuste:

Em que:

$$
n=\frac{n_{0}}{1+\frac{n_{0}}{N}}
$$

$\mathrm{n}=$ tamanho mínimo final da amostra

$\mathrm{N}=$ tamanho da população

Adotou-se o instrumento de coleta de dados - Pesquisa de Percepção (adaptado), o qual foi adotado como um dos pilares para elaboração do índice de universidade empreendedoras 2017, realizado pela Brasil Júnior (instância que representa as empresas juniores brasileiras), com o apoio de professores da Universidade de São Paulo - USP, da consultoria McKinsey 
Brasil, as organizações Ministério da Educação (MEC), Ministério da Ciência, Tecnologia, Inovações e Comunicações (MCTIC), Fórum Nacional de Gestores de Inovação e Transferência de Tecnologia (FORTEC), Serviço Brasileiro de Apoio às Micro e Pequenas Empresas (SEBRAE), Associação Nacional de Entidades Promotoras de Empreendimentos Inovadores (Anprotec), Empresa Brasileira de Pesquisa e Inovação Industrial (Embrapii), Confederação Nacional do Comércio (CNC) e Ranking Universitário da Folha (RUF).

$\mathrm{Na}$ etapa quantitativa foram utilizados formulários online para a coleta das respostas e o primeiro contato com os alunos foi feito por meio de redes sociais como facebook e whatsapp. Foi obtido o retorno de 118 questionários respondidos e válidos, representando 41,99\% da amostra definida.

Para a análise dos dados foi utilizada a estatística descritiva e análise de correlação entre as dimensões estudadas. A correlação de Pearson (r) apresenta a relação linear entre variáveis e a variação no coeficiente é de -1 a 1 , em que o sinal apresenta a direção do relacionamento e o valor apresenta a força da relação entre as variáveis. Teóricos admitem diferentes classificações dos escores, mas em geral podem ser considerados significativos os valores acima de 0,50 e abaixo de -0,50 (FIGUEIREDO FILHO; SILVA JÚNIOR, 2009). Neste estudo, foram analisadas somente as correlações abaixo de -0,50 e acima de 0,50.

Além disso, utilizou-se a técnica nuvem de palavras para a análise e apresentação de dados. A nuvem de palavras classifica os termos por quantidade e apresenta proporcionalmente, por meio do tamanho da fonte, a incidência do conteúdo, que pode ser utilizada para categorizar rótulos, títulos, entre outros (LEMOS, 2016). Para a criação da nuvem de palavras foi utilizada a ferramenta online TagCrowd $\AA$.

\section{APRESENTAÇÃO E ANÁLISE DE RESULTADOS}

A proposta do presente estudo é avaliar se universidades e centros universitários privados de Belo Horizonte estimulam o empreendedorismo, levando-se em consideração o ponto de vista discente. Dos 118 questionários respondidos, 63,56\% dos entrevistados foram do sexo masculino, enquanto $36,44 \%$ foram do sexo feminino. A maior parte dos respondentes são alunos de graduação da IES 1 , com $47,46 \%$ das respostas. A Tabela 1 apresenta a relação de proporção de estudantes de cada instituição.

Tabela 1 - Proporção de respondentes por instituição

\begin{tabular}{cc}
\hline Instituição & Entrevistados (\%) \\
\hline IES1 & $47,46 \%$ \\
IES2 & $16,94 \%$ \\
IES3 & $16,10 \%$ \\
IES4 & $13,56 \%$ \\
IES5 & $4,23 \%$ \\
IES6 & $1,69 \%$ \\
\hline Fonte: Dados da pesquisa (2019)
\end{tabular}

A maior parte dos estudantes cursa Engenharia Civil 47,46\%, seguido por Sistemas de Informação, com 18,64\% (Tabela 2). 
Tabela 2 - Respondentes por Curso

\begin{tabular}{lc}
\hline \multicolumn{1}{c}{ Curso } & Alunos (\%) \\
\hline Engenharia Civil & $47,46 \%$ \\
Sistemas de Informação & $18,64 \%$ \\
Engenharia de Produção & $14,41 \%$ \\
Engenharia Mecânica & $12,71 \%$ \\
Engenharia de Computação & $2,54 \%$ \\
Engenharia de Minas & $1,69 \%$ \\
Engenharia Metalúrgica & $0,85 \%$ \\
Engenharia Química & $0,85 \%$ \\
Engenharia Ambiental & $0,85 \%$ \\
\hline
\end{tabular}

Fonte: Dados da pesquisa (2019)

A infraestrutura oferecida pelas instituições foi considerada boa por grande parte dos alunos: 51,69\% avaliaram como boa a qualidade das salas de aula, 58,47\% os laboratórios de informática, $29,66 \%$ os laboratórios de pesquisa e 39,83\% os espaços de convivência disponíveis. A biblioteca disponível foi considerada excelente por $49,15 \%$, por outro lado, $21,19 \%$ consideraram o restaurante como regular e 38,14\% afirmaram que não há transporte interno na universidade. A disponibilidade de acesso à internet foi avaliada como boa por cerca de $30 \%$ dos alunos, enquanto a velocidade foi considerada regular por $27,19 \%$.

Quando comparadas as instituições pesquisadas no que diz respeito à infraestrutura, adotando uma escala de 5 pontos, em que 1 representa a característica "péssima" e 5 a característica "excelente", obtiveram-se os seguintes resultados (Tabela 3).

Tabela 3 - Infraestrutura da IES

\begin{tabular}{l|c|l|l|l|l|l|c|c}
\hline \multicolumn{1}{c}{ Atributos/ Instituições } & \multicolumn{1}{c}{ IES1 } & \multicolumn{1}{c}{ IES2 } & \multicolumn{1}{c}{ IES3 } & \multicolumn{1}{c}{ IES4 } & \multicolumn{1}{c}{ IES5 } & \multicolumn{1}{c}{ IES6 } & $\begin{array}{c}\text { Média por } \\
\text { atributo }\end{array}$ \\
\hline Salas de aula & 4,05 & 4,15 & 4,33 & 4,20 & 3,88 & 5,00 & $\mathbf{4 , 2 7}$ \\
Biblioteca & 4,43 & 4,45 & 4,42 & 3,20 & 4,56 & 4,50 & $\mathbf{4 , 2 6}$ \\
Laboratórios de informática & 4,20 & 4,20 & 3,83 & 3,60 & 3,88 & 4,50 & $\mathbf{4 , 0 4}$ \\
Laboratórios de pesquisa e & 4,05 & 4,32 & 3,92 & 3,20 & 2,88 & 4,50 & $\mathbf{3 , 8 1}$ \\
experimentação & & & & & & & $\mathbf{3 , 7 1}$ \\
Espaços abertos ou de convivência & 3,75 & 3,70 & 3,58 & 3,00 & 4,25 & 4,00 & $\mathbf{2 , 5 3}$ \\
Restaurante ou lanchonete & 3,04 & 2,79 & 0,11 & 2,50 & 4,19 & 3,00 & $\mathbf{3 , 1 6}$ \\
Disponibilidade acesso internet & 3,31 & 2,00 & 2,67 & 2,20 & 3,75 & 5,00 & $\mathbf{2 , 7 0}$ \\
Velocidade acesso internet & 3,11 & 2,90 & 2,58 & 1,80 & 3,31 & 2,50 & $\mathbf{2 , 0}$ \\
Média Geral por IES & 3,74 & 3,56 & 3,18 & 2,96 & 3,84 & 4,13 & $\mathbf{3 , 5 6}$ \\
\hline
\end{tabular}

Fonte: Dados da pesquisa (2019)

As instituições apresentam uma boa avaliação por parte dos discentes no quesito infraestrutura, com média geral 3,56. Entre todos os atributos investigados, os que apresentaram as menores médias gerais foram a velocidade de acesso à internet e o restaurante ou lanchonete (2,70 e 2,53, respectivamente).

O atributo que obteve melhor avaliação por partes dos discentes acerca da infraestrutura oferecida foram as salas de aula $(4,27)$, seguido pela biblioteca $(4,26)$. Uma boa estrutura propicia maior conforto aos alunos e os possibilitam desenvolver melhor suas atividades, além disso, uma boa biblioteca auxilia os alunos ao longo do seu curso com materiais importantes 
para um estudo mais aprofundado. Os alunos avaliaram como bons os laboratórios de informática e os de pesquisa e experimentação presentes em sua universidade. A média dos atributos avaliados foram de 4,04 e 3,81, respectivamente.

Por fim, a instituições que obtiveram maior média geral foram IES5 e IES6, de modo que, sob a perspectiva do aluno, essas instituições possuem boa infraestrutura para o desenvolvimento de suas atividades.

No que diz respeito à participação em atividades extracurriculares (Tabela 4), do total de pesquisados, 44,07\% não havia participado de nenhuma atividade extracurricular durante a graduação. Do envolvimento com atividades extracurriculares, destacam-se os projetos de extensão, uma vez que $29,66 \%$ disseram ter participado de algum em sua graduação.

Tabela 4 - Projetos ao longo da graduação

\begin{tabular}{lc}
\hline Projetos extracurriculares & Entrevistados (\%) \\
\hline Nenhum & $44,07 \%$ \\
Projetos de extensão & $29,66 \%$ \\
Monitoria & $20,34 \%$ \\
Empresa júnior & $10,17 \%$ \\
Iniciação científica & $9,32 \%$ \\
Atléticas & $6,78 \%$ \\
Movimento estudantil & $5,08 \%$ \\
Liga universitária & $4,24 \%$ \\
Liga acadêmica & $3,39 \%$ \\
Outros & $1,69 \%$ \\
\hline
\end{tabular}

Fonte: Dados da pesquisa (2019)

Quando questionados acerca do envolvimento dos estudantes de sua instituição com atividades empreendedoras, 38,14\% afirmaram que não sabem se existe esse engajamento, enquanto $34,75 \%$ afirmam que os estudantes estão envolvidos com o empreendedorismo. Em relação ao apoio do centro acadêmico do curso ao empreendedorismo universitário, 63,56\% afirmam que há esse apoio. No entanto, quando questionados se o Diretório Central dos Estudantes oferece esse apoio, $47,46 \%$ demonstram não saber.

A diversidade na universidade (étnica, gênero, classe social e região geográfica de origem) é considerada como fundamental para o empreendedorismo acadêmico por 38,98\% dos respondentes e $38,14 \%$ acreditam que a diversidade contribui muito para esse, ou seja, cerca de $80 \%$ consideram que a diversidade na instituição é importante para o desenvolvimento do empreendedorismo

Os alunos avaliaram que a principal característica que influencia a universidade a ser mais empreendedora é praticar a diversidade social, com $43,22 \%$, seguida pela diversidade geográfica 40,68\%. Por outro lado, 34,75\% acreditam que a diversidade étnica é fundamental para influenciar a universidade a ser mais empreendedora, 33,05\% considera que a diversidade de gênero é fundamental.

Em relação à metodologia de ensino da instituição, 45,76\% concordam parcialmente que essa contribui para o desenvolvimento de competências empreendedoras. Ademais, 37,29\% concordam parcialmente que a grade curricular do curso contribui para o desenvolvimento dessas competências. Por outro lado, $34,74 \%$ discordam totalmente que sua instituição oferece uma grade flexível para se engajar em atividades extracurriculares. Quando perguntados qual seria a grade curricular e metodologia de ensino ideal, a maioria dos alunos afirmou que seria uma grade curricular mais flexível e uma metodologia mais prática. 
Dos alunos pesquisados, 50\% concordam parcialmente que possuem postura empreendedora e 34,74\% acreditam que o ecossistema universitário em que estudam influenciou positivamente para o desenvolvimento de suas competências empreendedoras. Em relação ao questionamento de possuir um empreendimento atualmente, 5,93\% afirmaram que possuem uma empresa funcionando e 43,22\% responderam que pretendem abrir alguma empresa no futuro e, por outro lado, 6,78\% afirmaram que não pretendem abrir um negócio (Tabela 5).

Tabela 5 - Empreendimento Próprio

\begin{tabular}{lc}
\hline Se possui ou pretende abrir uma empresa & Alunos (\%) \\
\hline Pretendo abrir no futuro & $43,22 \%$ \\
Nunca tive uma empresa & $40,68 \%$ \\
Não pretendo abrir uma & $6,78 \%$ \\
Sim apenas uma & $5,93 \%$ \\
Vazias & $2,54 \%$ \\
Sim, mais de uma & $0,85 \%$ \\
\hline
\end{tabular}

Fonte: Dados da pesquisa (2019)

Em relação à postura empreendedora dos alunos de sua universidade, 38,98\% concordam parcialmente que os alunos possuem postura empreendedora. Já em relação à participação para o crescimento de um projeto na universidade, $29,66 \%$ concordam parcialmente que tiveram participação significativa para o desenvolvimento desse.

Quando comparadas as instituições pesquisadas no que diz respeito à postura empreendedora do discente, adotando uma escala de 5 pontos, em que 1 representa a característica "péssima" e 5 a característica "excelente", obtiveram-se os seguintes resultados (Tabela 6).

Tabela 6 - Postura empreendedora dos discentes

\begin{tabular}{|c|c|c|c|c|c|c|c|}
\hline Atributos/ Instituições & IES1 & IES2 & IES3 & IES4 & IES5 & IES6 & $\begin{array}{c}\text { Média por } \\
\text { atributo }\end{array}$ \\
\hline $\begin{array}{l}\text { Inconformismo com a realidade } \mathrm{e} \\
\text { disposição para transformá-la }\end{array}$ & 3,98 & 3,85 & 4,16 & 3,40 & 3,93 & 3,50 & 3,80 \\
\hline Visão para oportunidades & 4,05 & 4,35 & 4,37 & 4,20 & 4,20 & 3,50 & 4,11 \\
\hline Pensamento inovador e criativo & 3,78 & 3,8 & 4,21 & 4,40 & 3,93 & 3,00 & 3,85 \\
\hline Coragem para tomar risco & 3,84 & 4,15 & 4,32 & 3,40 & 4,00 & 3,50 & 3,87 \\
\hline Curiosidade & 4,39 & 4,55 & 4,53 & 3,60 & 4,20 & 4,50 & 4,30 \\
\hline $\begin{array}{l}\text { Facilidade de comunicação das ideias de } \\
\text { sociabilidade }\end{array}$ & 3,84 & 4,25 & 3,79 & 3,20 & 3,93 & 4,00 & 3,84 \\
\hline Apoio a iniciativas empreendedoras & 4,11 & 4,05 & 4,11 & 3,8 & 4,07 & 5,00 & 4,19 \\
\hline Média Geral por IES & 4,00 & 4,14 & 4,21 & 3,71 & 4,03 & 3,86 & 3,99 \\
\hline
\end{tabular}

Fonte: Dados da pesquisa (2019)

Os alunos das IES2, IES3 e IES5 apresentaram as maiores médias em relação à postura empreendedora do discente. Ao comparar o ranking das IES investigadas no referido quesito com a dimensão infraestrutura, observa-se que não há relação direta entre os dois aspectos. Esse resultado vai de encontro aos achados de Salume et al. (2019) em que a instituição que 
apresentou a mais alta pontuação na infraestrutura, também mostrou os melhores resultados nos quesitos relativos à postura empreendedora discente.

$\mathrm{O}$ atributo curiosidade obteve a maior média geral (4,30), o que demonstra que os estudantes se consideram questionadores e ambiciosos por conhecimento. Referente ao quesito "Pensamento inovador e criativo", os alunos da instituição IES6 consideram uma característica não tão presente neles próprios.

Em relação ao quesito "coragem de tomar riscos", os discentes das instituições IES3 e IES2 apresentaram as maiores médias. A respeito do inconformismo com a realidade e a disposição para transformá-la, os estudantes apresentaram uma média geral de 3,80.

Questionados acerca da postura empreendedora dos professores, 22,88\% concordam totalmente que esses possuem postura empreendedora e $28,81 \%$ concordam totalmente que os docentes possuem pensamento criativo e inovador. Ademais, $67,80 \%$ concordam totalmente que seus professores possuem experiência no mercado de trabalho.

Ao se investigar qual o principal motivo que faria o entrevistado permanecer na universidade, o mais citado foi qualidade, seguido de conhecimento, diploma e ensino, como pode ser observado na nuvem de palavras (Figura 4).

Figura 4 - Motivos para permanecer na universidade

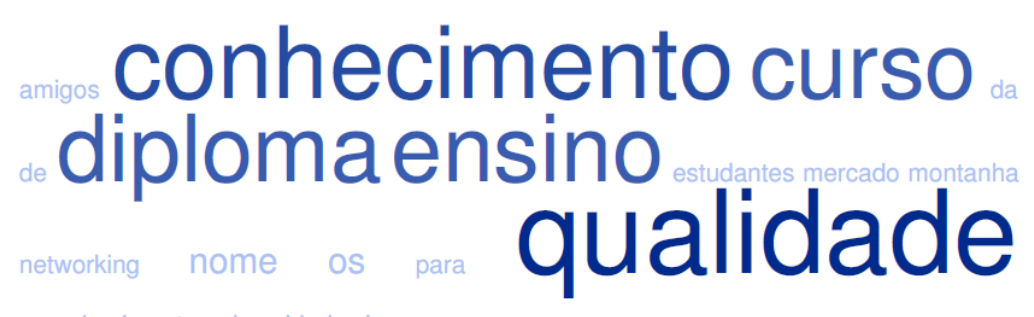

Fonte: Dados da pesquisa (2019)

Em relação aos principais problemas que fariam com que deixassem a universidade, o mais citado foi financeiro (Figura 5).

Figura 5 - Problemas que fariam sair da universidade

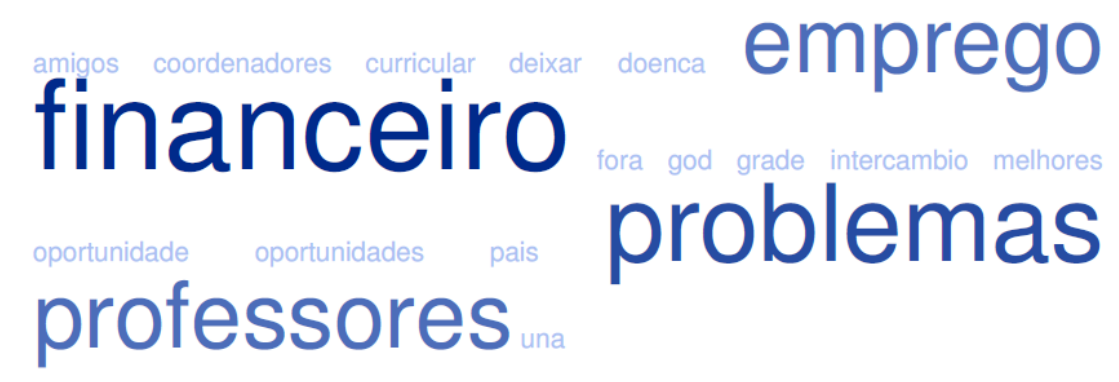

Fonte: Dados da pesquisa (2019)

No estudo, foram calculadas correlações entre todos os fatores pesquisados, entretanto, para a análise consideraram-se os resultados mais relevantes, ou seja, correlações acima de 0,50 e abaixo de -0,50. Quando se observam as correlações entre as diversas dimensões apresentadas, 
percebe-se que todas foram positivas, de forma que quando uma variável aumenta a outra tem o mesmo comportamento.

A correlação entre os atributos "possuir postura empreendedora" e "apoiar iniciativas empreendedoras" $(0,5277)$ demonstra que os alunos que têm características empreendedoras apoiam iniciativas empreendedoras.

O apoio do Diretório Central dos Estudantes da universidade ao empreendedorismo universitário está relacionado com o centro acadêmico do curso também apoiar o empreendedorismo na instituição $(0,6592)$ e com os estudantes estarem envolvidos com iniciativas empreendedoras $(0,5222)$. O centro acadêmico incentivar o empreendedorismo está relacionado com os estudantes estarem envolvidos com atividades empreendedoras $(0,5304)$. Os professores apoiarem iniciativas empreendedoras está relacionado ao Diretório Central dos Estudantes darem apoio ao empreendedorismo universitário $(0,6023)$.

Desse modo, o auxílio do diretório central dos estudantes é importante para o centro acadêmico do curso incentivar o empreendedorismo universitário e também os estudantes se envolverem em iniciativas empreendedoras. Esse envolvimento também está relacionado com o apoio do centro acadêmico ao empreendedorismo. O incentivo ao empreendedorismo do Diretório está relacionado com professores apoiarem iniciativas empreendedoras.

A universidade que oferece uma grade curricular flexível para o discente se engajar em atividades extracurriculares está associada com a metodologia de ensino que contribui para o desenvolvimento de competências empreendedoras $(0,5053)$ e ao aluno se considerar alguém com visão para oportunidades $(0,5529)$. Uma grade curricular flexível para participar de atividades extracurriculares possui ligação com uma metodologia de ensino que se preocupa com o desenvolvimento de competências empreendedoras, podendo uma grade flexível influenciar para uma metodologia empreendedora ou vice-versa. Além disso, a grade mais flexível possibilita aos alunos maior visão para oportunidades ao poderem se engajar em outras atividades.

A grade curricular como facilitadora para o desenvolvimento de competências empreendedoras está relacionada com a metodologia de ensino que contribui para o desenvolvimento dessas competências $(0,7869)$ e com os professores do curso possuírem postura empreendedora $(0,5034)$. Uma grade curricular que contribui para o desenvolvimento de competências empreendedoras se conecta com uma metodologia que desenvolve competências empreendedoras. Além disso, professores com postura empreendedora podem influenciar para que a grade e/ou metodologia desenvolva competências empreendedoras. Outra hipótese é de que esses professores sejam atraídos por uma grade e metodologias empreendedoras.

Professores possuírem postura empreendedora está associado com esses serem inconformados com a realidade e dispostos a transformá-la $(0,5381)$, terem visão para oportunidades $(0,5735)$, terem pensamento inovador e criativo $(0,5640)$, terem capacidade de realização $(0,5215)$, terem coragem de tomar riscos $(0,6480)$, terem curiosidade $(0,5297)$, terem facilidade de comunicação de ideias e sociabilidade $(0,6151)$ e apoiarem iniciativas empreendedoras $(0,6562)$. Desse modo, professores com postura empreendedora possuem características associadas a empreendedores. 


\section{CONSIDERAÇÕES FINAIS}

Conforme estabelecido na introdução desse artigo, o objetivo da presente pesquisa foi, a partir da percepção dos alunos, levantar e comparar as estruturas e iniciativas de instituições de ensino superior de Belo Horizonte, que visam estimular o empreendedorismo. $\mathrm{O}$ estabelecimento desse objetivo central se baseou na constatação de que, cada vez mais, as Universidades estão sendo estimuladas a criar estruturas internas de apoio a iniciativas empreendedoras discentes, adotar metodologias de ensino mais ativas, desenvolver ações extracurriculares para formação de competências empreendedoras e, além de tudo isso, estabelecer relações extramuros que facilitem a criação de novos negócios.

AIES possui uma missão de estimular o empreendedorismo e ser um berço de novos negócios e, como apresentado por autores ao longo do estudo, faz-se necessário que a instituição implemente diversas iniciativas para o estímulo do empreendedorismo, para que esse esteja presente em todos os cursos e em todas as esferas e ela seja realmente uma universidade empreendedora.

A partir dos resultados encontrados, percebe-se que os alunos consideram que a instituição de ensino onde estudam possui uma boa infraestrutura e que a metodologia de ensino e a grade curricular contribuem para esses obterem competências empreendedoras. Entretanto, os alunos expressaram a necessidade de uma grade curricular mais flexível para se engajar em atividades extracurriculares e uma metodologia mais prática.

Os dados mostraram baixo envolvimento dos alunos com empreendedorismo, o que pode ser comprovado na medida em que mais de $38 \%$ dos entrevistados não souberam dizer se a IES em que estudam possuem incentivos ou apoio ao empreendedorismo. Esse resultado corrobora os achados de Salume et al. (2019), os quais investigaram alunos do curso de Administração e descobriram que mais de 50\% também desconhecem as iniciativas empreendedoras promovidas pelas instituições que estudam.

Quando observadas as correlações entre as variáveis do estudo, percebe-se que o apoio do diretório central dos estudantes, do centro acadêmico do curso, como também por parte dos professores influenciam o envolvimento do estudante em iniciativas empreendedoras. Desse modo, ao estruturar um programa de empreendedorismo, além de se atentar para a criação de estruturas como incubadoras e centros de inovação, a IES deve pensar nesses atores como parceiros estratégicos para o desenvolvimento do empreendedorismo na universidade.

De maneira geral, os resultados mostraram que ainda há o que ser feito para que os alunos se envolvam e cultivem a mentalidade empreendedora no ambiente universitário. Importante destacar que processo de desenvolvimento de mentalidade empreendedora nos discentes não é consequência de esforço individual do docente ou da instituição, mas representa esforço conjunto dos atores institucionais.

É sugerido que em estudos futuros possa se investigar quais são as práticas de empreendedorismo mais eficientes para o incentivo e estímulo ao empreendedorismo utilizadas em universidades e centros universitários privados de Belo Horizonte. Além disso, outra sugestão é ampliar o estudo, tendo como amostra alunos de cursos de ciências humanas e biológicas, em que o empreendedorismo não é tão abordado como em cursos de Engenharia e Tecnologia. 


\section{REFERÊNCIAS}

ALMEIDA, Mariza Costa; TERRA, Branca; ALENCAR, Maria Simone de Menezes. Proposição e validação de indicadores de universidade empreendedora. Pesquisa Brasileira em ciência da informação e bibliografia, João Pessoa, v.11, n.2.p.038-046, set. 2016. ANDRADE, Renato Fonseca de; TORKOMIAN, Ana Lúcia Vitale. Fatores de influência na estruturação de programas de educação empreendedora em instituições de ensino superior. Anais do II Egepe, p.299-311, Londrina/PR, novembro/2001. Disponível em: http://www.oni.uerj.br/media/downloads/EMP2001-39\%20(1).pdf. Acesso em out. 2018. AUDY, JORGE. A inovação, o desenvolvimento e o papel da Universidade. Estudos avançados, São Paulo, v. 31, n. 90, p. 75-87, maio 2017.

AUDY, Jorge. Educação Superior e os parques científicos e tecnológicos: Inovação, Universidade e Relação com a sociedade. Porto Alegre: EDIPUCRS, 2009. Disponível em: http://www.pucrs.br/edipucrs/cplp/arquivos/audy.pdf. Acesso em mar. 2019.

BRASIL. Ministério da Educação. Censo da educação superior 2016. Brasília, DF: Ministério da Educação, 2017. Disponível em: http://portal.inep.gov.br/artigo//asset_publisher/B4AQV9zFY7Bv/content/mec-e-inep-divulgam-dados-do-censo-daeducacao-superior-2016/21206. Acesso em: 15 jun. 2018.

CASADO, F. L.; SILUK, J. C. M.; ZAMPIERI, N. L. V. Universidade Empreendedora e desenvolvimento regional sustentável: proposta de um modelo. Revista Administração UFSM, Santa Maria, v.5, edição especial, p.633-650, dez. 2012.

ETZKOWITZ, Henry; ZHOU, Chunyan. Hélice Tríplice: inovação e empreendedorismo universidade-indústria-governo. Estudos avançados, São Paulo, v. 31, n.90, p. 23-48, maio 2017. Disponível em http://www.scielo.br/scielo.php?script=sci_arttext\&pid=S010340142017000200023. Acesso em abr. 2019.

FIGUEIREDO FILHO, Dalson Brito; SILVA JUNIOR, José Alexandre. Desvendando os Mistérios do Coeficiente de Correlação de Pearson (r). Revista Política Hoje, [S.1.], v. 18, n. 1, jan. 2010. ISSN 0104-7094. Disponível em: https://periodicos.ufpe.br/revistas/politicahoje/article/view/3852. Acesso em: 25 jun. 2019. FILION, L. J. Empreendedorismo: empreendedores e proprietários-gerentes de pequenos negócios. Revista de Administração - USP, São Paulo, v. 34, n. 2, p. 5-28, abr./jun.1999. FONSECA, João José Saraiva da. Metodologia da pesquisa científica. Fortaleza: UEC, 2002.

GIL, Antônio Carlos. Métodos e técnicas de pesquisa social. 6. ed. São Paulo: Atlas, 2008. > IPIRANGA, Ana Sílvia Rocha; FREITAS, Ana Augusta Ferreira de; PAIVA, Thiago Alves. O empreendedorismo acadêmico no contexto da interação universidade - empresa - governo. Cadernos EBAPE.BR, Rio de Janeiro, v. 8, n. 4, artigo 7, p. 676-693, dez. 2010.

LEITE, A. G. da C.; DAMA, R. A.; GRIEBELER, M. P. D. As iniciativas empreendedoras da unijuí e sua contribuição para o desenvolvimento econômico e social regional: uma análise da instituição a partir dos parâmetros de universidade empreendedora. In: COLÓQUIO INTERNACIONAL SOBRE GESTÃO UNIVERSITÁRIA NAS AMÉRICAS, 13, Repositório Institucional UFSC, [ ], 2013. Disponível em: https://repositorio.ufsc.br/handle/123456789/114916. Acesso em mar. 2019. LEMOS, L. M. P. Nuvem de tags como ferramenta de análise de conteúdo: uma experiência com as cenas estendidas da telenovela Passione na internet. Revista Lumina, Juiz de Fora, v. 10, n. 1, abr. 2016 
MUNIZ, C.N.S. Atitude empreendedora e suas dimensões. 2008. Dissertação (Mestrado em Administração). Universidade de Brasília, Brasília, 2008.

MARTENS, Cristina Dai Prá; FREITAS, Henrique. A influência do ensino do Empreendedorismo nas intenções de direcionamento profissional dos estudantes de Curso Superior: uma avaliação a partir da Percepção dos alunos. In: SIMPÓSIO DE GESTÃO DA INOVAÇÃO TECNOLÓGICA, 24, 2006, Gramado. Anais [...]. Gramado: ANPAD, 2006, p$1-17$.

NOVO, Luciana Florentino; MELO, Pedro Antônio de. Universidade Empreendedora: fortalecendo os caminhos para a responsabilidade social. In: COLOQUIO INTERNACIONAL SOBRE GESTION, Buenos Aires. Repositório Institucional UFSC, Santa Catarina, 2014.

OLIVEIRA, Anna Gabriela Miranda de; MELO, Marlene Catariana de Oliveira Lopes; MUYLDER, Cristiana Fernandes de. Educação empreendedora: O Desenvolvimento do empreendedorismo e inovação social em instituições de ensino superior. Revista Administração em Diálogo, São Paulo, v.18, n.1, p.29-56, Jan/Fev/Mar/Abr 2016. Disponível em: https://revistas.pucsp.br/rad/article/view/v18i1.12727/0. Acesso em jan. 2019. PARREIRA, Pedro Miguel. et al. Representações sociais do empreendedorismo: o papel da formação na aquisição de competências empreendedoras. Revista Ibero-Americana de saúde e envelhecimento, Évora, Portugal, v. 1, n.3, p. 266 - 285, dez. 2015.

SALUME, Paula K.; GUIMARÃES, Liliane de O.; JUNQUEIRA, Luis Renato; RODRIGUES, Thiago Marques. Universidade Empreendedora: Análise de Estruturas e Iniciativas de Estímulo ao Empreendedorismo no Ensino Superior. Anais [...]. Enangrad Uberlândia/MG, agosto/2019, p. 1-18.

SANTOS, Marcos Pereira. Contributos da extensão universitária brasileira à formação acadêmica docente e discente no século XXI: um debate necessário. Revista Conexão UEPG, Ponta Grossa, v. 6, n.1, jan./dez. 2010. Disponível em: https://revistas.apps.uepg.br/index.php/conexao/article/view/3731. Acesso em nov. 2018. SCHAEFER, Ricardo; MINELLO, Ítalo Fernando. Educação Empreendedora: premissas, objetivos e metodologias. Revista pensamento contemporâneo em Administração, Rio de Janeiro, v. 10, n.3, p. 60-81, jul./set. 2016. Disponível em: http://periodicos.uff.br/pca/article/view/11270/pdf. Acesso em abr. 2019.

SEBRAE; ENDEAVOR. Empreendedorismo nas Universidades Brasileiras. Relatório de Pesquisa. SEBRAE; ENDEAVOR, 2016. [online]. Disponível em: https://endeavor.org.br/ambiente/pesquisa-universidades-empreendedorismo2016/?gclid=CjwKCAjw44jrBRAHEiwAZ9igKG1sD_XKBcI6vTYjXmf8Z0k8baajZmA7tA1mhKDvTPfSXpKyXMa1hoCBo4QAvD_BwE. Acesso em dezembro de 2018.

SEBRAE; IBPQ. Global Entrepreneurship Monitor - Empreendedorismo no Brasil: 2017. Relatório de Pesquisa. Curitiba, 2017. [online]. Disponível em: https://m.sebrae.com.br/Sebrae/Portal\%20Sebrae/Anexos/Relatório\%20Executivo\%20BRASI L_web.pdf. Acesso em janeiro de 2019.

TAVARES, Carlos Eduardo Moreira; MOURA, Gilnei Luiz de; ALVES, Juliano Nunes. Educação empreendedora e a geração de novos negócios. Rio Grande do Sul, 2013.

Disponível em: http://www.eumed.net/cursecon/ecolat/br/13/empreendedorismo.html. Acesso em nov. 2018. 